\title{
National Survey of Pharmacy and Therapeutic Committee in Saudi Arabia: Formulary Management System
}

\author{
Yousef Ahmed Alomi* iD, The Former \\ General Manager of General Administration \\ of Pharmaceutical Care, The Former Head, \\ National Clinical Pharmacy and Pharmacy \\ Practice, The Former Head, Pharmacy R \& D \\ Administration, Ministry of Health, Riyadh, \\ SAUDI ARABIA. \\ Sultan Mohammed Al-Jarallah, Head, \\ Ambulatory Care Pharmacy, Oncology and \\ Hematology Clinical Pharmacist, Pharmaceutical \\ Care Department, Security Forces Hospital, \\ Riyadh, SAUDI ARABIA. \\ Rasha Abdelsalam Elshenawy, BCS. Pharm \\ BCPS (AQ-ID), CPHQ, M.SC., TQM (AUC), SIDP, \\ CEO of FADIC, Ministry of Health, Makkah, \\ SAUDI ARABIA. \\ Faiz A Bahadig Rph, Informatics Pharmacist, \\ Pharmaceutical Care Department, \\ King Abdulaziz Medical City-WR-Jeddah, \\ Ministry of National Guard, SAUDI ARABIA.
}

\section{Correspondence:}

Dr. Yousef Ahmed Alomi, The Former General Manager of General Administration of Pharmaceutical Care, The Former Head, National Clinical pharmacy and pharmacy practice, The Former Head, Pharmacy $R$ \& D Administration, Ministry of Health, Riyadh, SAUDI ARABIA.

Phone no: +966504417712 E-mail:yalomi@gmail.com

Received: 03-05-2019;

Accepted: 27-06-2019

Copyright: $\odot$ the author(s), publisher and licensee International Journal of Pharmacology and Clinical Sciences. This is an open-access article distributed under the terms of the Creative Commons Attribution Non-Commercial License, which permits unrestricted non-commercial use, distribution, and reproduction in any medium, provided the original work is properly cited.

This is an open access article distributed under the terms of the Creative Commons Attribution-NonCommercial-ShareAlike 4.0 License

Access this article online

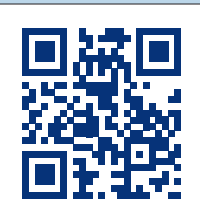

www.ijpcs.net

DOI:

10.5530/ijpcs.2019.8.50

\begin{abstract}
Objective: Formulary management is an integrated patient care process which enables physicians, pharmacists and other healthcare professionals to work together to promote clinically sound cost-effective medication therapy and positive therapeutic outcomes. Effective use of healthcare resources can minimize overall medical costs, improve patient access to more affordable care and provide an improved quality of life. A formulary not only includes a list of medications and medication-associated products but also includes medication-use policies, important ancillary drug information, decision support tools and organizational guidelines. Therefore, in this study, we aimed to provide the guiding principles for the Formulary Management System at Ministry of Health (MOH) hospitals in Saudi Arabia. Methods: This is a 4-month cross-sectional national survey of Pharmacy and Therapeutic Committee at $\mathrm{MOH}$ hospitals in Saudi Arabia. The survey consisted of two parts: the first part collected demographic information and the second part contained 93 questions divided into four domains. The scope, structure and responsibilities, the formulary management system, the evaluation of drug formulary and decision-making and the committee meetings organization and management. The electronic survey was distributed to 50 drug information centers at $\mathrm{MOH}$ hospitals. It analyzed the formulary management system at $\mathrm{MOH}$ hospitals in Saudi Arabia through Survey Monkey system. Results: A total of 50 drug information centers responded to our questionnaire. The statement with highest score was related to the committee formulary system of medications usage through ensuring the safety of prescribing, distribution, administration and monitoring of medications (3.8); the process for managing drug product shortages (3.76); and the medications are requested for the addition or deletion from the drug formulary (3.68). Most of the hospitals had an open drug formulary (30 (60\%)), with remaining responders having closed drug formulary $(20(40 \%))$ with the total number of medications in the drug formulary (300-899) at 32 (64\%) of the responded hospitals. The average score of type of method related to drug usage evaluation statements was 3.36, with the statement with high average score was review of medication error report (3.94) and review of medication sentinel incident reports (3.48), whereas the statement with lowest score was an investigational drug therapy approved (2.88). Conclusion: Two-thirds of the hospitals had open drug formulary. Drug utilization evaluation system should review for the majority of the hospital. update the formulary management system required with close monitoring for all $\mathrm{MOH}$ hospitals in Saudi Arabia.
\end{abstract}

Keywords: National Pharmacy and Therapeutic Committee, Ministry of Health, Saudi Arabia, Formulary Management System.

\section{INTRODUCTION}

Drug Formulary System is defined as "an ongoing process whereby a health care organization, through its physicians, pharmacists and other health care professionals, establishes policies on the use of drug products and therapies and identifies drug products and therapies that are the most medically appropriate." ${ }^{[1]}$ According to the definition provided by the CBAHI, a drug formulary is "an approved list of medications and associated information related to medication use."[2] According to the definition provided by the ASHP, drug formulary "is a continually updated list of medications and related information, representing the clinical judgment of pharmacists, physicians and other experts in the diagnosis and treatment of disease and promotion of health." ${ }^{[3]}$ A drug formulary not only includes a list of medications and medication-associated products but also contains the medication-use policies, important ancillary drug information, decision support tools and organizational guidelines. ${ }^{[4]}$ The American Academy of Managed Care Pharmacy identified the formulary management as "an integrated patient care process which enables physicians, pharmacists and other health care professionals to work together to promote clinically sound, cost-effective medication therapy and positive therapeutic outcomes. Effective use of health care resources can minimize overall medical costs, improve patient access to more affordable care and provide an improved quality of life." ${ }^{[5]}$ In Germany, the study of the structure and activities of the DCs that include the drug formulary management survey shows that DCs at German hospitals vary considerably with regard to their structure and activities, which is probably 
due to the nondefined legal situation in contrast to other European countries, e.g., the UK or France. Moreover, a very few papers have been published describing German hospital DCs and formularies. ${ }^{(6)}$ The number of voting members of the DC increases with respect to hospital size, which might be associated with a higher number of specialties. In university hospitals, the broad range of clinical specialties seems to be reflected in a high number of members in DC and this also seems to be related to higher drug expenditures per patient per day. Furthermore, university hospital DCs do not exercise a strict drug utilization policy, as shown by the low percentage of university DCs fulfilling the "efficiency criteria". ${ }^{[6]}$

In Spanish hospitals, the study of formulary management is a part of the activity, structure and procedures of the PTC. All hospitals have PTCs. The following primary documents are produced by the PTC in Spanish hospitals: drug formularies, therapeutic interchange guidelines and procedures governing the performance of the committees. There were no significant differences in the availability of these documents per the size of the hospital or the hospital's university or public status. ${ }^{[7]}$ Some studies have reported that effective formulary management is a crucial role in the healthcare system and the role of the PTC in managing the formulary medication is significant. The WHO identified the PTC at district and hospital level as one of the pivotal models to promote rational medicine use and formulary management. WHO recommends that all therapeutic classes on formulary management are reviewed annually to increase its effectiveness. ${ }^{[8]}$ The study in the Western Pacific Region (WPR) showed that nearly half of the hospitals in the WPR are currently not had meetings. The WHO recommends to review their formulary at least once a year and they do not have a systematic method for evaluating the evidence of addition or deletion medication from drug hospital formulary. Common reasons given by hospitals for not having a formulary were that the government did not require a hospital formulary; private hospitals generally had no restrictions on prescribers; and small hospitals did not have the resources to develop a formulary. The WPR study concluded that a greater number of hospitals in the WPR had implemented formularies and PTC. Although formularies are commonly used, their effectiveness may be limited, as formularies are often not linked to standard treatment guidelines or the best available evidence. ${ }^{[9]}$ Therefore, in this study, we aimed to explore the formulary management system at $\mathrm{MOH}$ hospitals in Saudi Arabia, by focusing on the use of formulary systems in hospitals and healthcare systems and provide the guiding principles for the effective formulary management.

\section{METHODS}

This is a 4-month cross-sectional national survey of PTC at $\mathrm{MOH}$ hospitals in Saudi Arabia. The survey consisted of two parts: the first part collected demographic information and the second part has 93 questions divided into the following four domains: domain 1: scope, structure and responsibilities; domain 2: formulary management system including the assessment of medication use policies and procedures, the formulary assessment, the drug formulary sections and triggers of DUE; domain 3: evaluation of drug formulary and decision-making; and domain 4: committee meetings, organization and management. This survey was derived from the previous literature, local regulation and ASHP standards of PTC and formulary system. ${ }^{[1,4,10-13]}$ The 5-point Likert response scale system with close-ended questions was used. The survey was distributed to 50 drug information centers at the $\mathrm{MOH}$ hospitals. Hospitals with all sizes/capacities or any type of specialty were included in the study. The survey was prepared in an electronic format and it analyzed the formulary management system through the Survey Monkey system.

\section{RESULTS}

A total of 50 drug information centers responded to the questionnaire. Of them, 48 (96\%) were Saudi and 2 (4\%) were non-Saudi centers. According to the gender distribution, $16(32 \%)$ were female and 34 (68\%) were male responders. According to the educational level, most of the responders had Bachelor Degree in Pharmacy (23 (46\%)), followed by Diploma in Pharmacy $(10(20 \%))$ and Master of Clinical Pharmacy $(9(18 \%))$ with more than three years experiences as pharmacist (45 (90\%)). The majority of the responders were PTC members $(21(43.8 \%))$ and vice-chairman (15 $(31.3 \%))$ with a duration of $1-6$ years $(64 \%)$ in PTC membership (Table 1). The majority of the responders belonged to hospitals with 100-299 beds $(28(56 \%))$ with accreditation from CBAHI (33 (66\%)), Saudi Commission of Health Specialties (15 (30\%)) and Joint Commission USA (13 (26\%)) (Table 2). The statements with highest average score were related to the Committee of Formulary System of Medications Usage through ensuring the safety of prescribing, distribution, administration and monitoring of medications (3.8), the process for managing drug product shortages (3.76) and the medications are requested for addition or deletion from the formulary (3.68) (Table 3). Most of the hospitals had an open drug formulary $(30(60 \%))$, with remaining

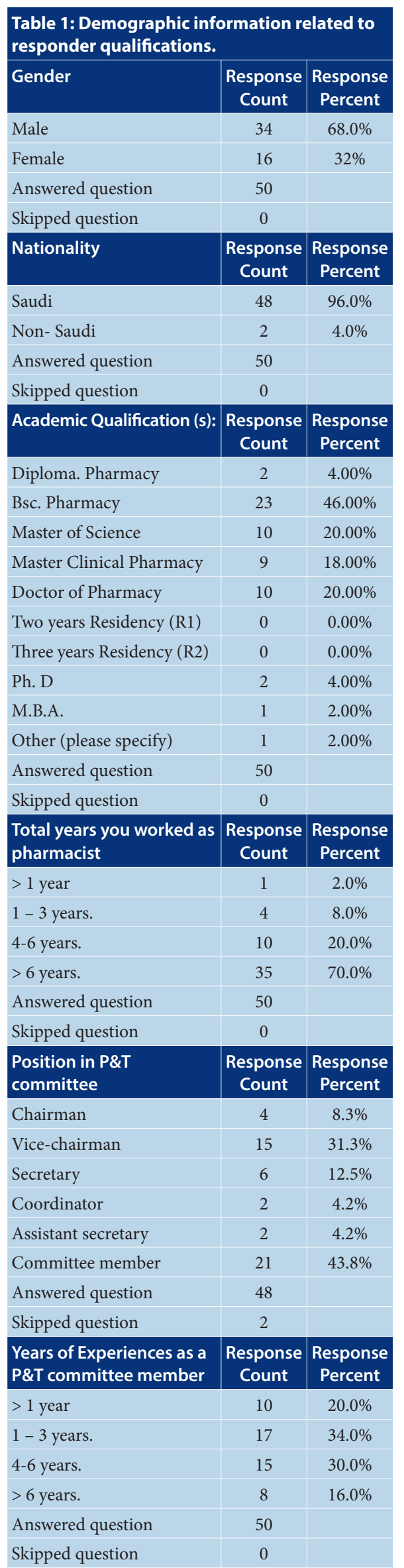




\begin{tabular}{|c|c|c|}
\hline $\begin{array}{l}\text { Number of beds at } \\
\text { your hospital }\end{array}$ & $\begin{array}{l}\text { Response } \\
\text { Count }\end{array}$ & $\begin{array}{c}\text { Response } \\
\text { Percent }\end{array}$ \\
\hline$<50$ & 4 & $8.0 \%$ \\
\hline $50-99$ & 6 & $12.0 \%$ \\
\hline 100-199 & 14 & $28.0 \%$ \\
\hline $200-299$ & 14 & $28.0 \%$ \\
\hline $300-399$ & 5 & $10.0 \%$ \\
\hline $400-499$ & 4 & $8.0 \%$ \\
\hline $500-599$ & 2 & $4.0 \%$ \\
\hline$=$ or $>600$ & 0 & $0.0 \%$ \\
\hline Medical City & 1 & $2.0 \%$ \\
\hline Answered question & 50 & \\
\hline Skipped question & 0 & \\
\hline $\begin{array}{l}\text { The hospital } \\
\text { accreditation }\end{array}$ & $\begin{array}{l}\text { Response } \\
\text { Count }\end{array}$ & $\begin{array}{c}\text { Response } \\
\text { Percent }\end{array}$ \\
\hline CBAHI & 33 & $66.0 \%$ \\
\hline Joint Commotion USA & 13 & $26.0 \%$ \\
\hline Canada & 0 & $0.0 \%$ \\
\hline $\begin{array}{l}\text { Saudi commission of } \\
\text { health specialties }\end{array}$ & 15 & $30.0 \%$ \\
\hline Non accredited & 11 & $22.00 \%$ \\
\hline Answered question & 50 & \\
\hline Skipped question & 0 & \\
\hline
\end{tabular}

responders having closed drug formulary (20 (40\%)) with the total number of medications in the drug formulary (300-899) at 32 (64\%) of the responded hospitals (Table 4). Most of the drug formulary book had adverse drug reaction section (39 (78\%)), drug-drug interaction section (26 (52\%)) and medication error section (22 $(44 \%))$ and rarely had clinical guidelines section (1 (2\%)). The committee provides drug formulary services mostly to inpatient services (46 (92\%)), outpatient services (41 (82\%)), emergency services $(36(72 \%))$ and rarely to home healthcare services (1 (2\%)) (Table 5). The average score of type of method related to DUE statements was 3.36, with the statement with high score was a review of medication error report (3.94) and review medication sentinel incident reports (3.48), whereas the statement with lowest score was an investigational drug therapy approved (2.88) (Table 6).

\section{DISCUSSION}

PTC has several functions and responsibilities that are included in formulary management and control based on the national and international pharmaceutical standards. The corporate and regional PTCs have been founded with explicit scopes and functions in the KSA. The formulary management system and control were the
Table 3: Assessment of medication use policies and procedures.

\begin{tabular}{|l|l|l|l|l|l|l|l|}
\hline Answer Options & Always & Often & Sometimes & Rarely & Never & $\begin{array}{c}\text { Rating } \\
\text { Average }\end{array}$ & $\begin{array}{c}\text { Response } \\
\text { Count }\end{array}$ \\
\hline
\end{tabular}

How medications are

15

15

11

7

2

3.68

50

to or deletion from

the formulary,

How medications are

11

10

14

12

3.33

49

reviewed for Addition

formulary, including who

performs the reviews, the process for developing, implementing and monitoring medicationuse guidelines,

Methods for ensuring the safe prescribing, distribution, administration and monitoring of medications,

Methods for selection of suitable Manufacturers for specific medications (a pharmacist shall be responsible for specifications for the quality, quantity and source of supply of all medications, chemicals, biological and pharmaceutical preparations

used in the diagnosis and treatment of patients)

The process for using nonformulary agents within the institution,

The process for managing drug product shortages,

The process of developing an organization-specific

MUE plan, Policies regarding specific medication-use processes (e.g., procurement, prescribing, distribution, administration, monitoring),

The process for disseminating medication-use policies and how users will be educated regarding the process

11

9

12

12

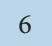

3.14

50

answered question

skipped question
50

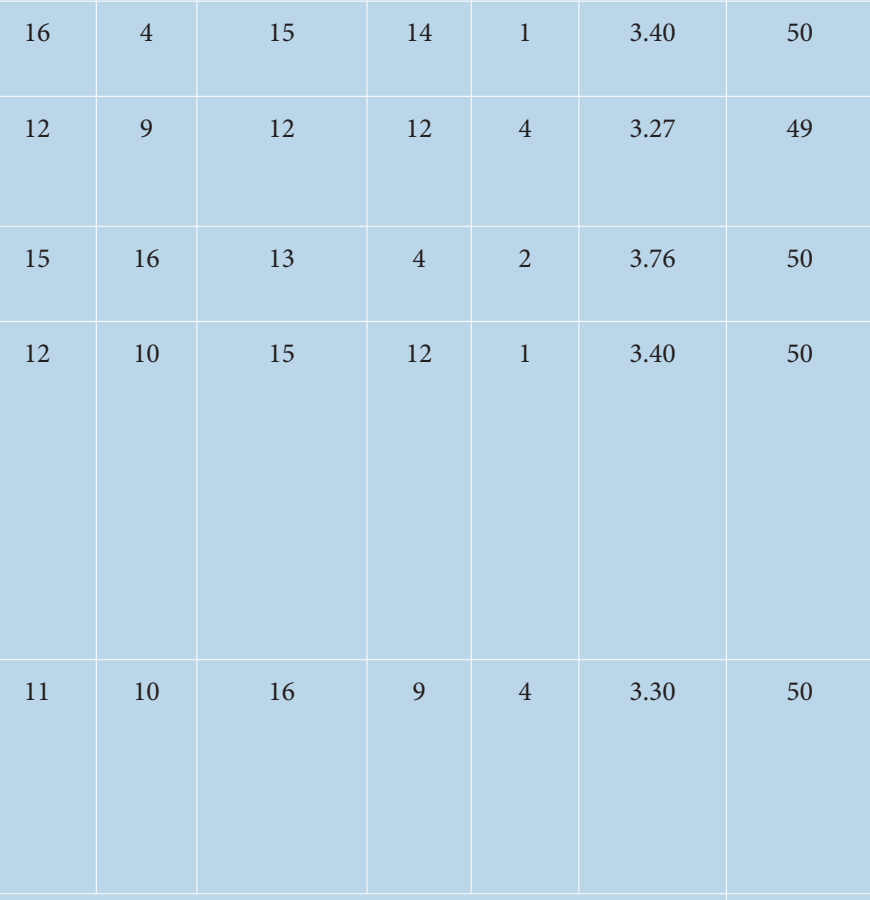

0 
Table 4: Type of formulary.

Answer Options

Open formulary: A list of medications which has no limitation

to access to a medication by a practitioner.

Close formulary: is a limited list of medications which may limit drugs to specific physicians, patient care areas, or disease states via formulary restrictions.

Other

answered question

skipped question

Number of drugs in the formulary.

Answer Options

$<100$

100-299

300-499

500-699

700-899

900-1099

1100-1299

1300-1499

1500-1699

1700-1899

$=$ or $>1900$

answered question

skipped question

\section{Table 5: The drug formulary sections.}

\section{Answer Options}

Adverse drug reactions

Drug-drug interactions

Medication errors

Lab preparation

Clinical guideline

Don't crush list,

pharmacological category

Non available of the above

answered question

skipped question

Service area(s) covered:

\section{Answer Options}

Inpatient pharmaceutical services

Recovery room

Operating room

Emergency room

Ancillary clinic(s)

Outpatient pharmaceutical services

Home care clinic

answered question

skipped question \begin{tabular}{l|l} 
Response Count & Response Percent
\end{tabular}

30

20

0

\begin{tabular}{l|l} 
Response Count & Response Percent
\end{tabular}

5

$10.0 \%$

3

$6.0 \%$

10

$20.0 \%$

11

$22.0 \%$

11

3

$22.0 \%$
Response Count

47

\section{Response Count}

39

26

22

1

1

1

1

7

20

27

36

13

41

1
$6.0 \%$

$4.0 \%$

$4.0 \%$

$6.0 \%$

$0.0 \%$

$0.0 \%$

50

0 primary functions of all PTCs at $\mathrm{MOH}$ hospitals. In this study, we explored the formulary management system. According to our results, most of the formulary control were the ensured the safety of medications of stages of drug process, drug shortage management and addition and deletion of a drug formulary. Those functions were clear and fits with the medication's safety program implementation and reporting of drug-related problems. The drug shortage management is almost a daily work of pharmacy services in practice. The regulatory aspects of addition and deletion of medications from the drug formulary was the primary and regular job of PTC. The statements with lowest scores in the formulary system were the selection of appropriate manufacturers which it does not need that because the Saudi Food and Drug Authority (SFDA) did the same job. However, the implementation of this element should be done to help the SFDA with their job. Moreover, the statement with lowest score regarding the formulary control system was the process of nonformulary requesting method and education of drug policy and usage not done adequately. These two methods are very critical to control requesting of medications and avoid misuse of drugs. According to the results of this study, more half of the hospitals used open formulary, which is not an appropriate formulary control system, which is different from previous study because the local PTC is less developed in Saudi Arabia than that of other country. ${ }^{[13]}$ The close formulary system in necessary to be implemented at all $\mathrm{MOH}$ hospitals. Most of the hospitals used $\mathrm{MOH}$ drug formulary as local formulary similar to previous study. ${ }^{[14,15]}$ Most of the drug formulary used had ADR, drug interactions and medications errors section, whereas pharmacological classification and clinical guidelines rarely were present. The essential of medications control not exist in the drug formulary. An updated design of $\mathrm{MOH}$ drug formulary is required. The formulary control system is mostly implemented at inpatient, outpatient and emergency services and this has also been reported in a previous study. ${ }^{[13]}$ It is rarely implemented at home healthcare services. The critical hospital services with Vision 2030 should be included in the formulary control system. The results of this study showed that the highest triggers used for DUE was medications errors, sentinel event and ADR reporting system because most of the hospitals that responded had implemented a medications safety program. While the monitory investigational drugs or treatment guidelines and approved Drug Utilization Evaluation (DUE criteria were the lowest implemented guidelines in the hospitals because the majority of the hospitals not currently fully implemented. All PTCs should revise the aforementioned 


\begin{tabular}{|c|c|c|c|c|c|c|c|}
\hline Answer Options & Always & Often & Sometimes & Rarely & Never & Rating Average & Response Count \\
\hline Review adverse drug reaction reports. & 15 & 10 & 13 & 5 & 7 & 3.42 & 50 \\
\hline Review medication sentinel incident reports. & 14 & 10 & 13 & 7 & 4 & 3.48 & 48 \\
\hline Review medication errors reports & 23 & 8 & 12 & 4 & 2 & 3.94 & 49 \\
\hline $\begin{array}{l}\text { Review investigational drug therapy approved by } \\
\text { institutional review board. }\end{array}$ & 9 & 10 & 10 & 8 & 13 & 2.88 & 50 \\
\hline answered question & & & & & & & 50 \\
\hline skipped question & & & & & & & 0 \\
\hline
\end{tabular}

triggers in order to closely monitor the medications and drug therapy.

\section{CONCLUSION}

The drug formulary management system conducted by the PTC is not adequately implemented at $\mathrm{MOH}$ hospitals. Some essential elements of drug formulary were missed. Targeting to activate the PTC formulary system at $\mathrm{MOH}$ institutions is required. The survey on the formulary management system at $\mathrm{MOH}$ hospitals is highly recommended at least once in every two years in the KSA.

\section{ACKNOWLEDGMENT}

None.

\section{CONFLICT OF INTEREST}

None.

\section{ABBREVIATIONS}

PTC: Pharmacy and Therapeutic Committee; UK: United Kingdom; MOH: Ministry of Health; DCs: Drug committees; CBAHI: Saudi Central Board for Accreditation of Healthcare Institutions; ASHP: American Society of Health-System Pharmacists; WHO: World Health Organization; ADR: Adverse drug reaction; DUE: Drug utilization evaluation; SFDA: Saudi Food and Drug Authority; KSA: Kingdom of Saudi Arabia.

\section{ORCID ID}

Yousef Ahmed Alomi org/0000-0003-1381-628X

https://orcid.

\section{REFERENCES}

1. American Society of Health-System Pharmacists Principles of a Sound Drug Formulary System. Best Pract Hosp Heal Syst Pharm. 2000;182-5.

2. Saudi Center Board for Accreditation for Healthcare Institutions (CBAHI). Medication Management (MM). In: National Hospital Standards. $2^{\text {nd }}$ Editio Saudi Central Board for Accreditation of Healthcare Institutions. 2016:194-211.

3. Tyler LS, Millares M, Wilson AL, Valentino A, Cole SW, Com P. ASHP statement on the Pharmacy and Therapeutics Committee and the formulary system. Am J Heal Pharm. 2008;65(24):2384-6.

4. Abazia DT, Anderson P, Azzopardi LM, Baker KR, Besier JL, Bootman JL, et al. ASHP statement on the pharmacy and therapeutics committee and the formulary system. Am J Heal Pharm. 2008:65(24):2384-6.

5. Johnson N. Formulary Management. 2010. Available from: http://www.amcp.org/WorkArea/Download Asset. aspx?id=9298\% 0Apapers2://publication/ uuid/6E57E589-B14E-4C41-BAA4-C7B660C12124

6. Thürmann PA, Harder S, Steioff A. Structure and activities of hospital drug committees in Germany. Eur J Clin Pharmacol. 1997;52(6):429-35.

7. Puigventós F, Santos-Ramos B, Ortega A,
Durán-García E. Structure and procedures of the pharmacy and therapeutic committees in Spanish hospitals. Pharm World Sci. 2010:32(6):767-75.

8. Vang C, Tomson G, Kounnavong S, SouthammavongT, Phanyanouvong A, Johansson R, et al. Improving the performance of Drug and Therapeutics Committees in hospitals-A quasi-experimental study in Laos. Eur J Clin Pharmacol. 2006:62(1):57-63.

9. Penm J, Chaar B, Dechun J, Moles R. Formulary systems and pharmacy and therapeutics committees in the Western Pacific Region: Exploring two Basel Statements. Am J Heal Pharm. 2013:70(11):967-79

10. Tyler LS, Cole SW, May JR, Miliares M, Valentino MA, Vermeulen LC, et al. ASHP Guidelines on the Pharmacy and Therapeutics Committee and the Formulary System. Am J Heal Pharm. 2008;65(13):1272-83.

11. Alomi YA, Alghamdi SJ, Alattyh RA. National Corporate Pharmacy and Therapeutic Committee at the Ministry of Health, Saudi Arabia. Pharmacol Toxicol Biomed Reports. 2019;4(3):24-7.

12. Alomi YA, Alghamdi SJ, Alattyh RA. National Drug Formulary of the Ministry of Health in Saudi Arabia. Pharmacol Toxicol Biomed Reports. 2019;4(3):28-30.

13. Mannebach MA, Ascione FJ, Gaither CA, Bagozzi RP, Cohen IA, Ryan ML. Activities, functions and structure of pharmacy and therapeutics committees in large teaching hospitals. Am J Heal Pharm. 1999;56(7):622-8

14. Gul W. PTC is important for the betterment of the hospital pharmacy. Innov Pharm Pharmacother. 2014;2(1):307-11.

15. Thürmann PA, Harder S, Steioff A. Structure and activities of hospital drug committees in Germany. Eur J Clin Pharmacol. 1997:52(6):429-35. 